\title{
Characterization of $\mathrm{pTMC}_{\mathrm{n}} \mathrm{LiPF}_{6}$ solid polymer electrolytes
}

\author{
P. C. Barbosa, L. C. Rodrigues, M. M. Silva*, M. J. Smith \\ Centro de Química, Universidade do Minho, Gualtar, 4710-057 Braga, Portugal \\ *nini@quimica.uminho.pt
}

\begin{abstract}
In this study the results our characterization of a solid polymer electrolyte based on poly(trimethylene carbonate), henceforth designated as $\mathrm{p}(\mathrm{TMC})$, and lithium hexafluorophosphate $\left(\mathrm{LiPF}_{6}\right)$ are described. Samples of solvent-free electrolytes were prepared with a range of concentration of guest salt using solvent casting from tetrahydrofuran and characterized by conductivity measurements, thermal analysis and electrochemical stability. Electrolytes based on this host polymer, with $\mathrm{LiPF}_{6}$, were obtained as mechanically robust, flexible, transparent and completely amorphous films.
\end{abstract}

\section{Introduction}

Polymer-based materials continue to attract significant attention as a basis for solid-state electrolytes in electrochemical devices such as batteries, display devices and sensors $[1,2]$. Generically, solid polymer electrolytes (SPEs) are solutions of salts with soft polar polymers such as poly(ethylene oxide) (PEO). Among the various types of polymer electrolyte systems used in lithium polymer batteries, SPEs have many advantages including high ionic conductivity, high energy density, very low leakage risk, no issues related to the presence of solvent, wide electrochemical stability windows, simplified processability and light weight. 
Since their discovery in the 1970 s, SPEs have been intensively studied $[3,4]$. It is generally accepted that ionic conduction is confined to the amorphous polymer fraction above their glass transition temperature, $\mathrm{T}_{\mathrm{g}}$, and is strongly coupled to the polymer segmental motion. A wide range of polymer hosts have been characterized in the search for a formulation that maximizes the amorphous fraction and results in lower $\mathrm{T}_{\mathrm{g}}$ values, thus increasing the level of ionic conductivity [5-8].

Large near-spherical polyatomic anions have attracted most attention as promising Li-salt anions for battery electrolytes through their ability to suppress ionpairing. So far, singly-charged anions such as $\mathrm{PF}_{6}{ }^{-}$have been adopted successfully in some Li-ion battery concepts. The solubilization of lithium hexafluorophosphate in the polycarbonate host has been shown to provide access to electrolyte compositions with encouraging electrochemical and physical characteristics[3].

In this present study, we therefore focus on how $\mathrm{p}(\mathrm{TMC})$ can influence the general properties of $\mathrm{p}(\mathrm{TMC})_{\mathrm{n}} \mathrm{LiPF} 6$ (the value of $\mathrm{n}$ represents the number of $\left((\mathrm{C}=\mathrm{O}) \mathrm{OCH}_{2} \mathrm{CH}_{2} \mathrm{CH}_{2} \mathrm{O}\right)$ units per lithium ion $)$, within the category of electrolytes based on $\mathrm{PEO}$, those incorporating the anion $\mathrm{PF}_{6}^{-}$have been extensively investigated to data [9-11]. The disadvantages associated with conventional PEO- based PEs, has grown considerably, the strategies for modification of the polymer architecture for improved the properties of the polymer electrolytes.

\section{Experimental}

\subsection{Materials}

High molar mass p(TMC) (3 x $10^{5} \mathrm{gmol}^{-1}$, Shell Chemicals, Houston, TX, USA) was dried by argon/vacuum purge cycles at $70{ }^{\circ} \mathrm{C}$ for 7 days. No further purification of 
the polymer matrix was carried out. Lithium hexafluorophosphate (Aldrich, anhydrous 99\%) was used without further purification and stored in a high integrity, dry argonfilled glovebox. THF (Aldrich, anhydrous 99.9\%, inhibitor-free) was dried over molecular sieves prior to use. All subsequent manipulations of salt, electrolyte samples preparations and measurements were carried out under a dry argon atmosphere.

\subsection{Sample preparation}

Homogeneous solutions of $\mathrm{p}(\mathrm{TMC})$ and lithium hexafluorophosphate were prepared by stirring known masses of polymer, lithium salt and a convenient volume of THF, in a small conical flask. The components were stirred for a period of at least $48 \mathrm{~h}$ within a dry argon-filled preparative glovebox. The resulting solutions were decanted into glass rings seated on flat teflon plate supports and the solvent was removed slowly by evaporation to form films of approximately $150 \mu \mathrm{m}$ thickness. Residual solvent was eliminated by drying using purge/heating cycles at $60{ }^{\circ} \mathrm{C}$. In accordance with current practice, an SPE formulation with $25-\left(\mathrm{O}=\mathrm{COCH}_{2} \mathrm{CH}_{2}-\mathrm{CH}_{2} \mathrm{O}\right)-$ monomer units per lithium ion was identified as $\mathrm{p}(\mathrm{TMC})_{25} \mathrm{LiPF}_{6}$.

\subsection{Measurements}

\subsubsection{DSC and TGA measurements}

Polymer electrolyte sections were removed from cast films and subjected to DSC analysis under a flowing argon atmosphere between 25 and $300^{\circ} \mathrm{C}$ at a heating rate of $5^{\circ} \mathrm{C} \cdot \mathrm{min}^{-1}$ using a Mettler DSC 821e instrument. All samples were presented for analysis in $40 \mu \mathrm{L}$ aluminium cans with perforated lids to permit the release and removal of the decomposition products. Samples for thermogravimetric studies were prepared in

a similar manner, transferred to open platinum crucibles and analyzed using a 
Rheometric Scientific TG 1000 thermobalance operating under a flowing argon atmosphere. A heating rate of $10^{\circ} \mathrm{C} \cdot \mathrm{min}^{-1}$ was used to analyze all the electrolyte samples.

\subsubsection{Impedance spectroscopy}

Total ionic conductivities of electrolyte samples were determined using a constant volume support equipped with gold blocking electrodes and located within a Buchi TO 50 oven. The sample temperature was evaluated by means of a type K thermocouple placed close to the electrolyte film and impedance measurements were carried out at frequencies between $65 \mathrm{kHz}$ and $500 \mathrm{mHz}$ using an Autolab PGSTAT-12 (Eco Chemie), over a temperature range from 20 to $90^{\circ} \mathrm{C}$. Measurements of conductivity were effected during heating cycles. The reproducibility of recorded conductivities was confirmed by comparing the results obtained for a sample subjected to two heatingcooling-heating cycles. The excellent reproducibility of the results obtained using this procedure demonstrated the correct operation of the support and the mechanical stability of the samples.

\subsubsection{Electrochemical stability}

Evaluation of the electrochemical stability window of electrolyte compositions was carried out within a dry argon-filled glovebox using a two-electrode cell configuration. The preparation of a $25 \mu \mathrm{m}$ diameter gold microelectrode surface by the conventional polishing routine was completed outside the glove box. The microelectrode was then washed with THF, dried with a hot-air blower and transferred to the interior of the glove box. Cell assembly was initiated by locating a freshlycleaned lithium disk counter electrode (10 mm diameter, $1 \mathrm{~mm}$ thick, Aldrich, $99.9 \%$ 
purity) on a stainless steel current collector. A thin-film sample of $\mathrm{p}(\mathrm{TMC})_{\mathrm{n}} \mathrm{LiPF}_{6}$ was centered over the counter electrode and the cell assembly completed by locating and supporting the microelectrode in the centre of the electrolyte disk. The assembly was held together firmly with a clamp and electrical contacts were made to the Autolab PGSTAT-12 potentiostat used to record voltammograms at a scan rate of $100 \mathrm{mVs}^{-1}$. All measurements were conducted at room temperature within a Faraday cage located inside the dry argon-filled glovebox.

\section{Results and discussion}

\subsection{Thermal behaviour of electrolytes}

Analysis of the thermograms of the $\mathrm{p}(\mathrm{TMC})_{\mathrm{n}} \mathrm{LiPF}_{6}$ electrolytes represented in Fig. 1 leads us to conclude that the samples with $n$ ranging from 100 to 5 are totally amorphous. At high salt concentration ( $n=2.5$ to 25$)$ thermal events are observed at temperatures greater than about $175^{\circ} \mathrm{C}$. The existence of these peaks may be associated with the thermal instability of $\mathrm{LiPF}_{6}$. The $\mathrm{LiPF}_{6}$ salt is thermally stable up to $150{ }^{\circ} \mathrm{C}$ (analysis not shown) in a dry inert atmosphere, and its decomposition path is a simple dissociation producing $\mathrm{LiF}$ as solid and $\mathrm{PF}_{5}$ as gaseous products. This behaviour is similar to that presented by Hui Yang et al [12]. An alternative explanation for the observation of endothermic peaks is that they are caused by fusion of a salt-polymer complex [3]. The attribution of the events to degradation is supported by thermogravimetric analysis and by observations reported for electrolytes with high salt concentration in the $\mathrm{PEO}_{n} \mathrm{LiPF}_{6}$ system [13]. In view of this supporting evidence the authors attribute the thermal effects observed in the $\mathrm{p}(\mathrm{TMC})_{\mathrm{n}} \mathrm{LiPF}_{6}$ system to degradation of the host polymer matrix. 
In the plot of Fig. 2 we observe that the Tgs of samples with $n>15$ are essentially the same. In contrast, with $\mathrm{n}<15$ the Tg of the $\mathrm{p}(\mathrm{TMC})$ segments suffers a significant increase with salt addition. In the polycarbonate system studied $\mathrm{T}_{\mathrm{g}} \mathrm{s}$ of electrolytes pass through a minimum and then rise at high salt content (Fig. 2). This observation suggests that significant interactions between the guest ionic species and the polymer host chains takes place at higher concentrations of lithium salt. This behaviour is similar to that presented by electrolytes based on the $\mathrm{p}(\mathrm{TMC})$ host and lithium tetrafluoroborate $\left(\mathrm{LiBF}_{4}\right)$, lithium hexafluoroarsenate $\left(\mathrm{LiAsF}_{6}\right)$, lithium triflate $\left(\mathrm{LiCF}_{3} \mathrm{SO}_{3}\right)$ and lithium iodide (LiI) systems [14-19]. The onset of thermal decomposition was estimated from thermogravimetric analysis using the conventional technique of extrapolation of the baseline and tangent of the curve to identify the temperature associated with the initiation of sample weight loss. DSC and TGA analysis are consistent with a minimum thermal stability of about $161^{\circ} \mathrm{C}$ for the $\mathrm{n}=2.5$ composition (Fig. 3). The results presented in Fig. 3 show a decrease in thermal stability with increasing salt concentration, confirming that the salt has a destabilizing influence on the matrix host. A higher fraction of residue above $500{ }^{\circ} \mathrm{C}$ is found with increasing salt. The source of the incomplete decomposition at high salt content is not clear, but is believed to be associated with the $\mathrm{PF}_{6}$ anion containing backbone [20].

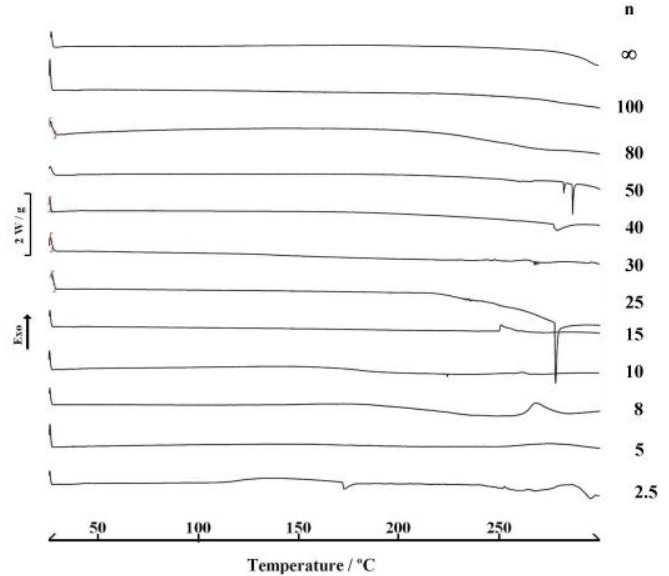

Figure 1. DSC thermograms of selected $\mathrm{p}(\mathrm{TMC})_{\mathrm{n}} \mathrm{LiPF}_{6}$ electrolytes 


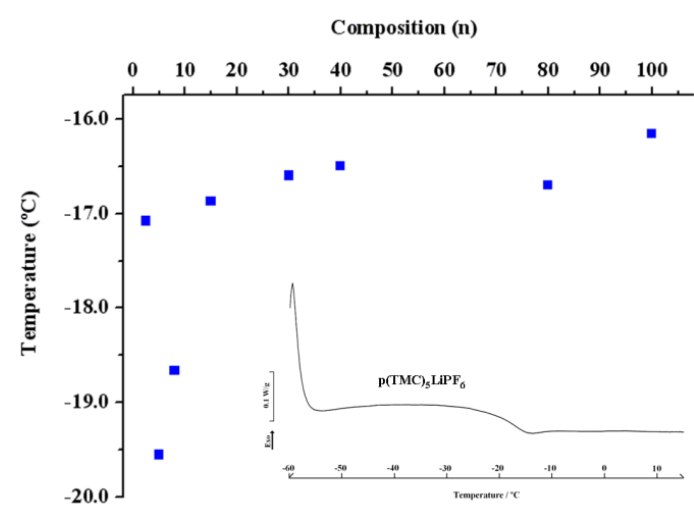

Figure 2. Tg of selected $\mathrm{p}(\mathrm{TMC})_{\mathrm{n}} \mathrm{LiPF}_{6}$ electrolytes. Inset illustrates thermogram of $\mathrm{p}(\mathrm{TMC})_{5} \mathrm{LiPF}_{6}$ composition.

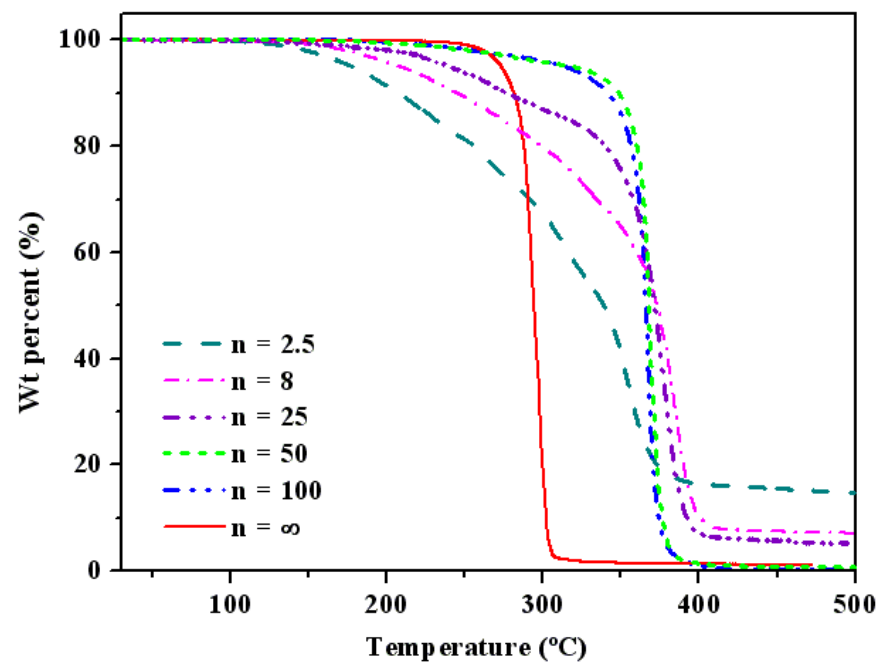

Figure 3. TGA curves of selected $\mathrm{p}(\mathrm{TMC})_{\mathrm{n}} \mathrm{LiPF}_{6}$ electrolytes.

\subsection{Ionic conductivity of electrolytes}

The ionic conductivities of various polymer electrolytes over the temperature range from 25 to $90{ }^{\circ} \mathrm{C}$ and as a function of salt are illustrated in Fig. 4. All compositions gave typical Arrhenius plots, similar to polyether-based amorphous polymer electrolytes, and contrasts with that of semi-crystalline materials based on the 
PEO host matrix. The combination of relatively high chain flexibility and polar coordinating atmos dispersed periodically on the polymer and result in the notable capacity of $\mathrm{p}(\mathrm{PMC})$ to dissolve very high salt compositions without salt precipitation. From the results presented in Fig. 4 it is possible to conclude that the most conducting sample of the series is $\mathrm{p}(\mathrm{TMC})_{5} \mathrm{LiPF}_{6}$. At about $98^{\circ} \mathrm{C}$, this electrolyte presents the highest conductivity of all the samples investigated $\left(4.79 \times 10^{-6} \mathrm{Scm}^{-1}\right)$ and at ambient temperature the ionic conductivity presented is approximately $1.78 \times 10^{-8} \mathrm{Scm}^{-1}$, a value similar to that reported by Magistris et al. [12]. At $57^{\circ} \mathrm{C}$ this electrolyte composition exhibits a conductivity of $6.5 \times 10^{-7} \mathrm{~S} \mathrm{~cm}^{-1}$ (Fig. 4), a value higher than those reported by Rietman et al. [21] for the $\mathrm{PEO}_{n} \mathrm{LiPF}_{6}$ system. This result was expected, as the PEObased electrolytes are typically poor conductors at ambient temperature due to the presence of crystalline material. At temperatures above about $70^{\circ} \mathrm{C}$ however the PEOcontaining electrolytes are better ionic conductors than the $\mathrm{p}(\mathrm{TMC})_{\mathrm{n}} \mathrm{LiPF}_{6}, \mathrm{SPEs}$.

The conductivity isotherms derived from these results are included in Fig. 5 and confirm that this electrolyte system behaves in a similar manner to that reported for other $\mathrm{p}$ (TMC) systems [14-19]. In compositions from about $\mathrm{n}=15$ to $\mathrm{n}=5$, the conductivity rises to a maximum and then falls rapidly in electrolytes with even higher salt content. The $\mathrm{p}(\mathrm{TMC})_{5} \mathrm{LiPF}_{6}$ composition also corresponds to the electrolyte with the lowest $T_{g}$, which means that the presence of the guest salt exerts a plasticizing effect on the polymer structure and increases the free-volume available to polymer chain segments. As the mechanism of ionic transport is directly dependant of the flexibility of the polymer chain, components that increase free volume may be expected to have a beneficial influence on conductivity. A further increase in salt content, beyond the salt composition associated with the electrolyte with the lowest $\mathrm{T}_{\mathrm{g}}$, results in an increase in lower internal chain rotation and a decrease in the segment mobility. The restrictions in 
the motion of the polymer chain segments, which are responsible for ion transport, explain the sudden decrease in conductivity, a fairly common observation in solventfree polymer electrolyte systems. Also this observation can be explained by the formation of associated ionic species (ion pairs or ion aggregates) and an increased tendency for ions to form bridging interactions between adjacent polymer chains (ionic crosslinking). Associated ionic species may be expected to show lower mobility than dissociated ions and the restriction of host matrix segment mobility also contributes to a reduction the conductivity. The conduction mechanism also can be explained by, is likely, to involve ion hopping between static sites. The validity of this observation it has been recognized by Shriver and co-workers $[22,23]$ to the behaviour of others polymers. Shriver [22] has argued that transport in a rigid polymer electrolyte possessing a carbonate unit is decoupled from the segmental motion in the polymer.

According to the classical study of Berthier et al [24] it has been recognized that ionic mobility is closely correlated with the viscoelastic properties of the host polymer and so the relative magnitude of $\mathrm{Tg}$ in these materials can be of considerable importance. The observed increase in $\mathrm{Tg}$ at lower values of $\mathrm{n}$ can be explained by the increase in number of bridging interactions which take place between adjacent polymer chains and guest salt species. Spectroscopic measurements on different salts $[25,26]$ have confirmed that charged clusters exist in electrolytes and that the formation of these aggregates depends on guest salt concentration and electrolyte temperature

The levels of ionic conductivity observed with the electrolytes proposed here are modest. The conductivity of these systems is too low for room temperature performances, likely because of poor salt dissociation, contrary to salts with oxygen, containing anions (for exemple $\mathrm{LiClO}_{4}, \mathrm{LiCF}_{3} \mathrm{SO}_{3}$ ). However, is could be interesting to investigate the system with $\mathrm{LiPF}_{6}$ as a new electrolyte for super ambient applications, 
choosing appropriated molar rations [13]. Like others authors $[12,16]$ the sample with $\mathrm{n}=30$ represents a good compromise between conductivity and low salt content. The SPEs must have an appropriate balance of properties if they are to be successful as device components. Also, it is important to emphasize that the system described in this paper represents materials with good performance for application in electrolytic component and the active solid state electrochromic layer.
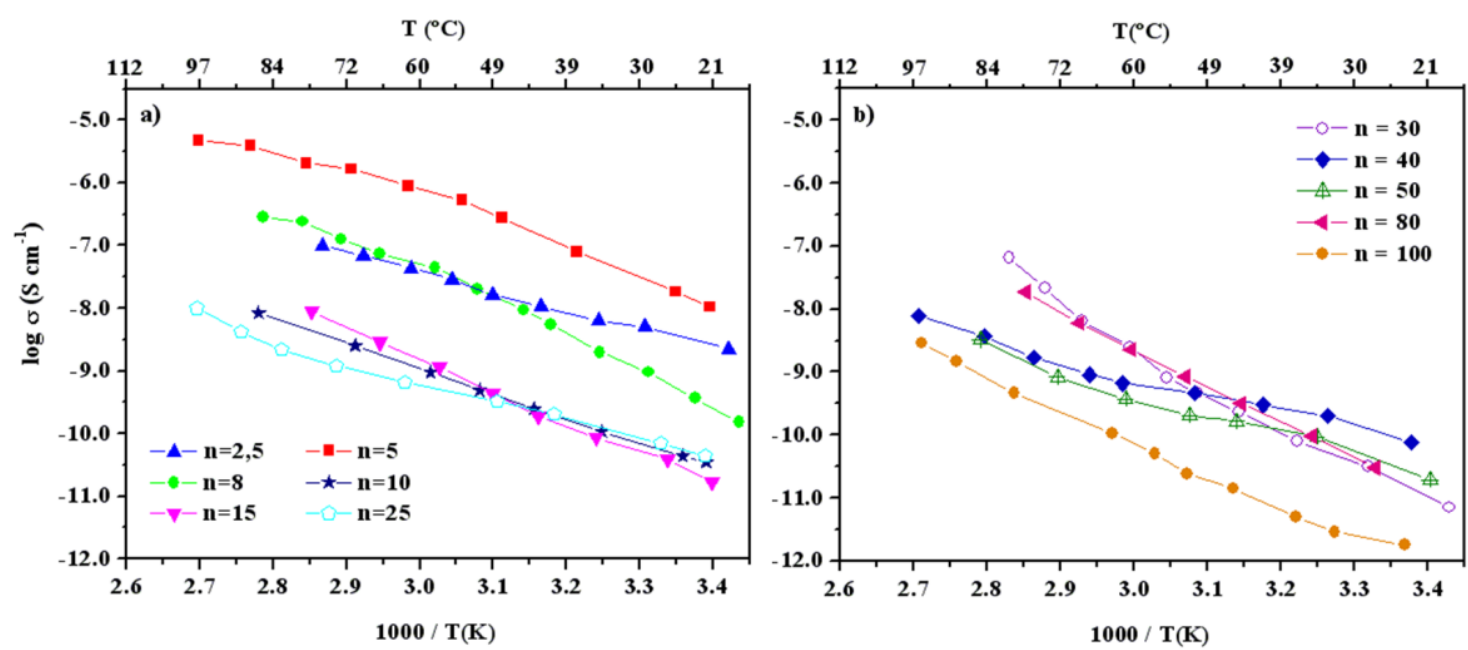

Figure 4. Variation of ionic conductivity with $1 / T$ for selected electrolyte compositions of $\mathrm{p}(\mathrm{TMC})_{n} \mathrm{LiPF}_{6}$.

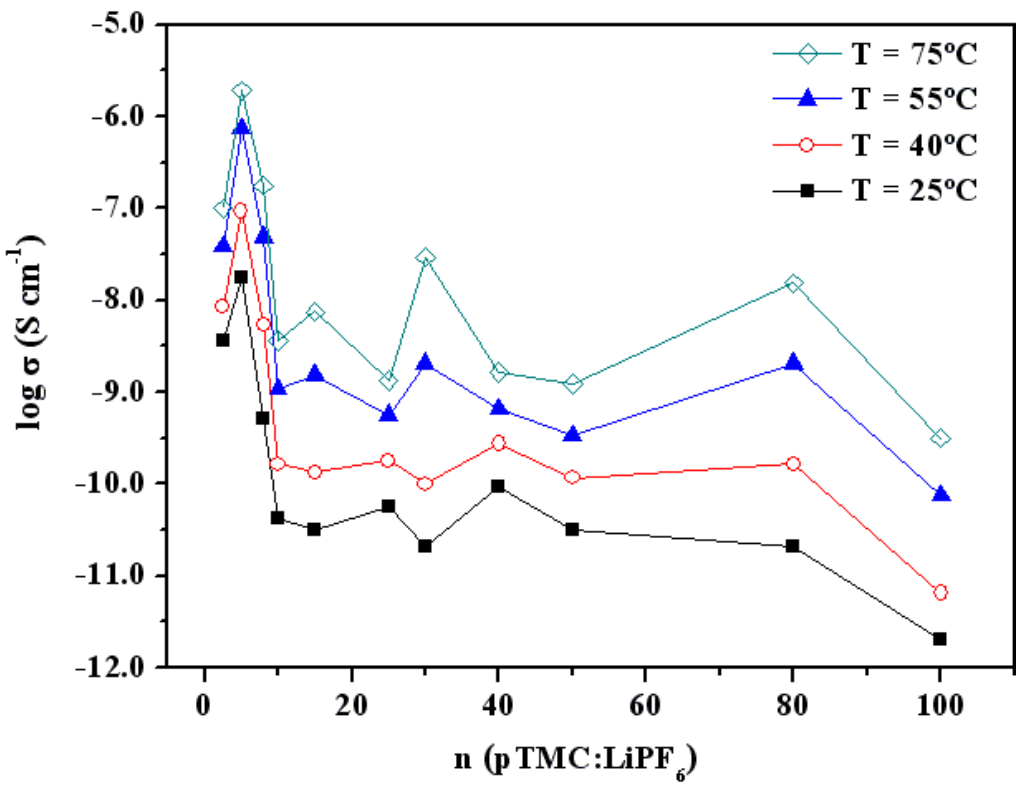


Figure 5. Composition dependence of the ionic conductivity of the $\mathrm{p}(\mathrm{TMC})_{n} \mathrm{LiPF}_{6}$ electrolytes.

\subsection{Electrochemical stability}

The electrochemical stability of the $\mathrm{p}(\mathrm{TMC})_{30} \mathrm{LiPF}_{6}$ electrolyte was determined by microelectrode cyclic voltammetry over the potential range -1.0 to $7.0 \mathrm{~V}$ (Figure 6). The potential limit for the electrolyte composition was determined as the potential at which a rapid rise in current was observed and where the current continued to increase as the potential was swept in the same direction. On the cathode sweep a low current peak at approximately $3.0 \mathrm{~V}$ vs. $\mathrm{Li} / \mathrm{Li}^{+}$was observed and attributed to the reduction of decomposition products that were formed at the anodic limit. Lithium deposition begins in the cathodic region at about $-0.5 \mathrm{~V}$ vs. $\mathrm{Li} / \mathrm{Li}^{+}$. The overall stability of the electrolyte is good with no electrochemical oxidation occurring at potentials less than $4.5 \mathrm{~V}$. This result confirms that the electrolyte system has sufficient electrochemical stability for application in practical primary and secondary cells.

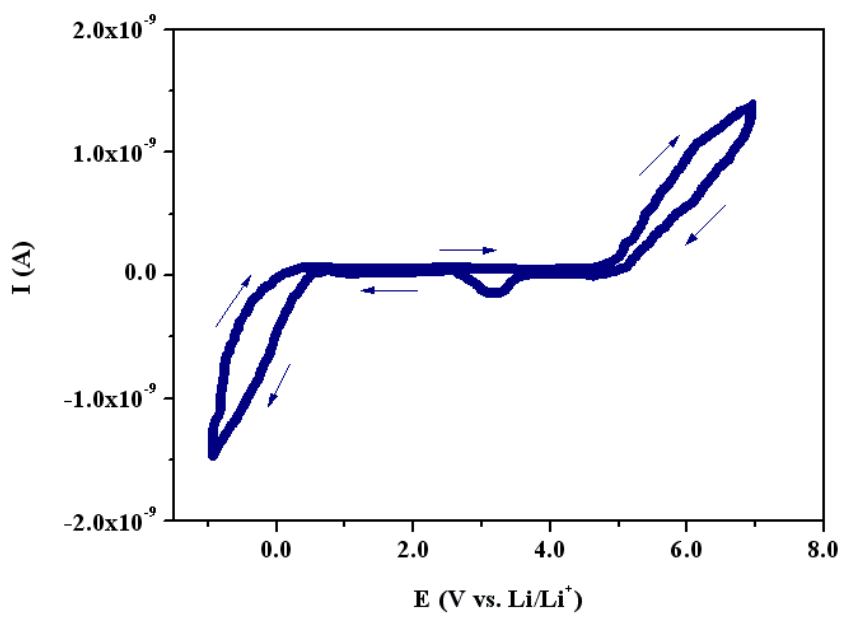


Figure 6. Voltammogram of $\mathrm{p}(\mathrm{TMC})_{30} \mathrm{LiPF}_{6}$ electrolyte at a $25 \mu \mathrm{m}$ diameter gold microelectrode versus $\mathrm{Li} / \mathrm{Li}^{+}$. Initial sweep direction is anodic and sweep rate is $100 \mathrm{mVs}^{-1}$.

\section{Conclusions}

The materials described in this study are completely amorphous and show a broad redox stability window of $4.5 \mathrm{~V}$. Mechanically the $\mathrm{p}(\mathrm{TMC})$ host matrix is sufficiently stable for use as a thin-film electrolyte layer in practical devices. Two further properties are worthy of comment. Electrolyte compositions in the range characterized are slightly adhesive and very transparent. We have shown that the polymer electrolytes discussed here exhibit also good thermal and mechanical properties. These additional features may provide additional advantages for their application in practical devices, particularly displays where optical transparency is of critical importance.

\section{Acknowledgements}

The authors are pleased to acknowledge the financial support provided by the University of Minho and the Fundação para a Ciência e Tecnologia (contracts POCI/QUI/59856/2004, POCTI/SFA/3/686, SFRH/BD/22707/2005 and SFRH/BD/38616/2007) for laboratory equipment and research staff.

\section{References}


[1] D. E. Fenton, J. M. Parker, P. V. Wright, Polymer 14 (1973) 589.

[2] P .G. Bruce (Ed.), Solid-state electrochemistry, Cambridge University Press, Cambridge, 1995.

[3] F. M. Gray, Polymer Electrolytes, RSC Materials Monographs, The Royal Society of Chemistry, Cambridge, 1997.

[4] P. M. Blonsky, D. F. Shriver, P. E. Austin, H. R. Allcock., J. Am. Chem. Soc., 106 (1984) 6854.

[5] J. R. MacCallum, C. A. Vincent, Editors, Polymer Electrolytes Reviews, London: Elsevier Applied Science. 1987, Ch.1, pp.1-22.

[6] C. J. Nelson, W. D. Coggio, H. R. Allcock, Chem. Mater. 3 (1991) 117.

[7] H. R. Allcock, S. E. Kuharcik, C. S. Reed, M. E. Napierala, Macromolecules 29 (1996) 3384.

[8] S. Vorrey and D. Teeters, Electrochim. Acta, 2003, 48, 2137.

[9] Z. Stoeva, I. Martin-Litas, E. Staunton, Y.G. Andreev, P. G. Bruce, J. Am.Chem.Soc., 125(15) (2003) 4619-4626.

[10]D. Brandell, A. Liivat, A. Aabloo, J. O. Thomas, Chem. Mater., 17 (2005)3673.

[11] D. Brandell, A. Liivat, A. Aabloo, J. O. Thomas, J. Chem. Mater., 15 (2005)4338.

[12] H. Yang, G. V. Zhuang, P.N. Ross Jr, J. Power Sources, 161 (2006)573-579.

[13] A. Magistris, P. Mustarelli, E. Quartarone, C. Tomasi, Solid State Ionics 136-137 (2000) 1241.

[14] M. M. Silva, S .C. Barros, M. J. Smith, J. R. MacCallum, J. Power Sources, 2002, 111, 52 .

[15] M. Armand, W. Gorecki, R. Andreani, in Second International Meeting on Polymer Electrolytes (ed. Scrosati, B.), Elsevier, London, 1989, 91-96.

[16] M. J. Smith, M. M. Silva, S. Cerqueira, J. R. MacCallum, Solid State Ionics, 140 (2001) 345 . 
[17] M. M. Silva, S. C. Barros, E. Fernandes, M. J. Smith, J. R. MacCallum, in Advanced Batteries and Super Capacitors, Eds., G. Nazri, R. Koetz, B. Scrosati, P. A. Moro and E. S: Takeuchi, The Electrochemical Society Proceedings Series PV2001-21, (2003) p. 476.

[18] S. Cerqueira Barros, M. M. Silva, M. J. Smith, J. R. MacCallum, Advanced Materials Forum II, Trans Tech Publications, Vols. 455-456 (2004) 596-601.

[19] M. M. Silva, S. Cerqueira Barros, M. J. Smith, J. R. MacCallum, Electrochimica Acta, 49 (2004) 1887.

[20] C. Y. Chiang, Y. J. Shen, M. J. Reddy, P. P. Chu, J. Power Sources, 123 (2003) 222-229.

[21] E. A. Rietman, M. L. Kaplan, R. J. Cava, Solid State Ionics, 17 (1985) 67.

[22] X. Wei, D. F. Shriver, Chem. Mater.,10 (1998) 2307.

[23] M. A. Ratner, D. F. Shriver, Chem. Rev., 88 (1998) 109.

[24] C. Berthier, W. Gorecki, M. Minier, M. Armand, J. M. Chabagno, P. Rigaud, Solid State Ionics, 11 (1983) 91-95.

[25] R. N. Mason, L. Hu, D. T. Glalzhofer, R. Frech, Solid State Ionics, 180 (2010) $1626-1632$.

[26] S. Rafendran, M. Sivakumar, R. Subadevi, Solid State Ionics, 167 (2004) 335-339. 


\section{Figure Caption list}

Figure 1. DSC thermograms of selected $\mathrm{p}(\mathrm{TMC})_{\mathrm{n}} \mathrm{LiPF}_{6}$ electrolytes

Figure 2. $\mathrm{Tg}$ of selected $\mathrm{p}(\mathrm{TMC})_{\mathrm{n}} \mathrm{LiPF}_{6}$ electrolytes. Inset illustrates thermogram of $\mathrm{p}(\mathrm{TMC})_{5} \mathrm{LiPF}_{6}$ composition.

Figure 3. TGA curves of selected $\mathrm{p}(\mathrm{TMC})_{\mathrm{n}} \mathrm{LiPF}_{6}$ electrolytes.

Figure 4. Variation of ionic conductivity with $1 / T$ for selected electrolyte compositions of $\mathrm{p}(\mathrm{TMC})_{n} \mathrm{LiPF}_{6}$.

Figure 5. Composition dependence of the ionic conductivity of the $\mathrm{p}(\mathrm{TMC})_{n} \mathrm{LiPF}_{6}$ electrolytes. 
Figure 6. Voltammogram of $\mathrm{p}(\mathrm{TMC})_{30} \mathrm{LiPF}_{6}$ electrolyte at a $25 \mu \mathrm{m}$ diameter gold microelectrode versus $\mathrm{Li} / \mathrm{Li}^{+}$. Initial sweep direction is anodic and sweep rate is $100 \mathrm{mVs}^{-1}$.

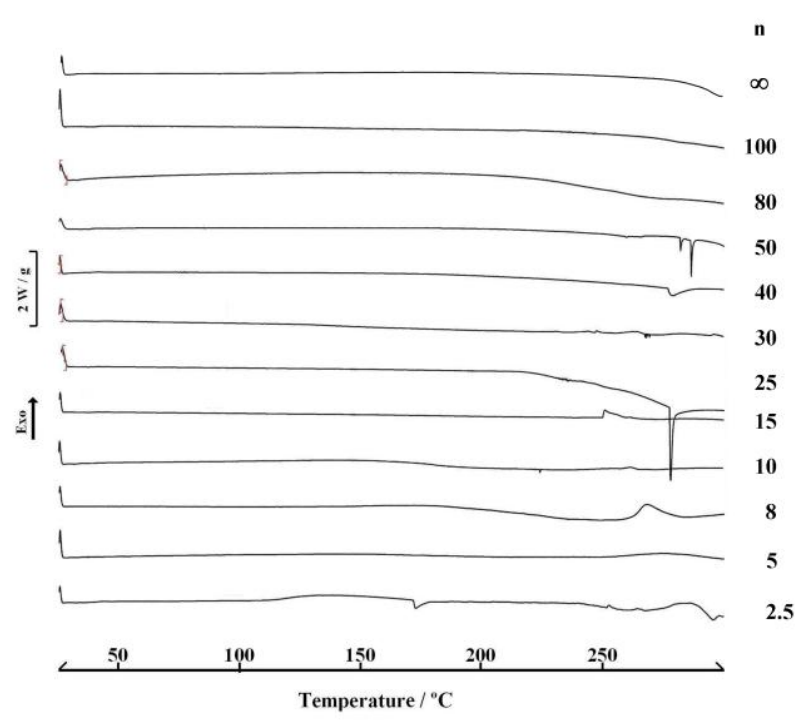

Figure 1. DSC thermograms of selected $\mathrm{p}(\mathrm{TMC})_{\mathrm{n}} \mathrm{LiPF}_{6}$ electrolytes 


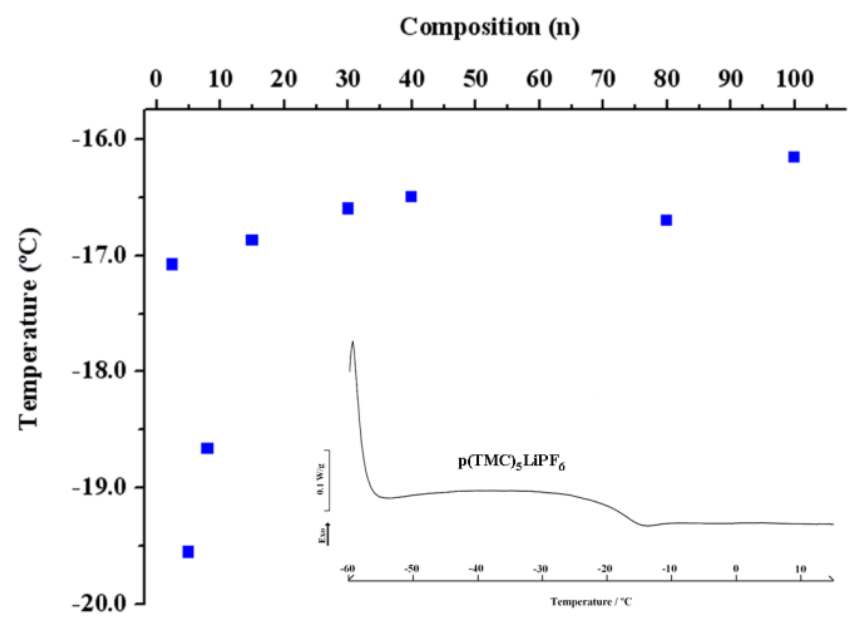


Figure 2. $\mathrm{Tg}$ of selected $\mathrm{p}(\mathrm{TMC})_{\mathrm{n}} \mathrm{LiPF}_{6}$ electrolytes. Inset illustrates thermogram of $\mathrm{p}(\mathrm{TMC})_{5} \mathrm{LiPF}_{6}$ composition.

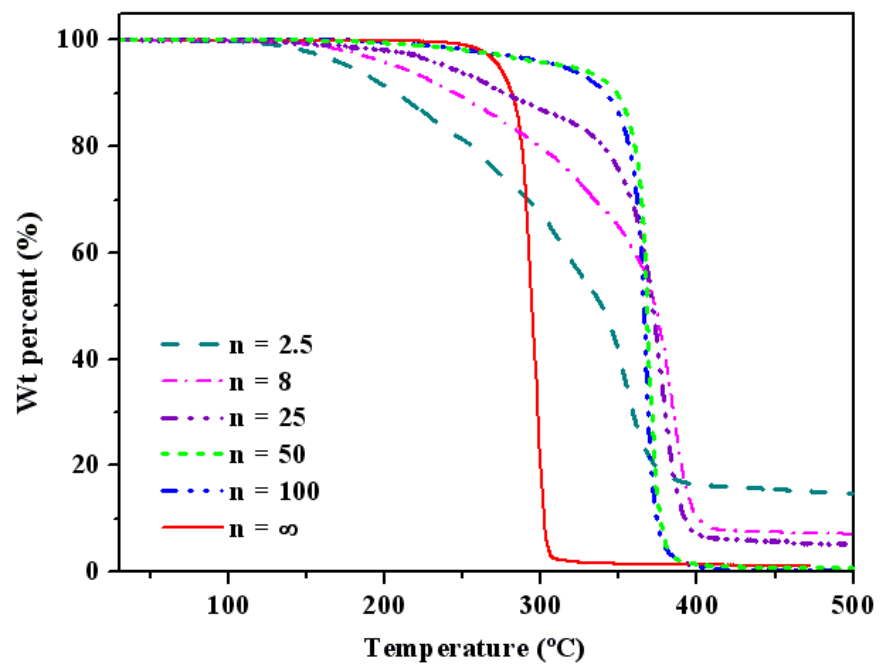

Figure 3. TGA curves of selected $\mathrm{p}(\mathrm{TMC})_{\mathrm{n}} \mathrm{LiPF}_{6}$ electrolytes. 

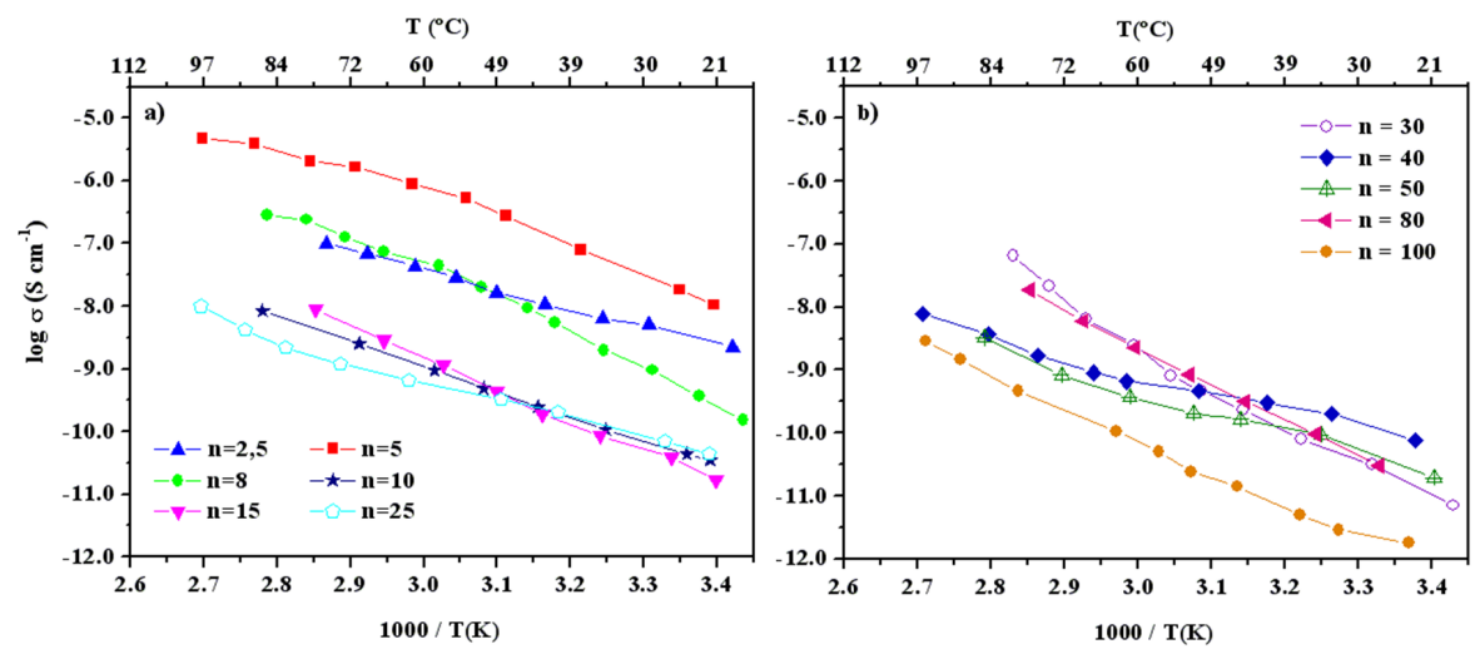

Figure 4. Variation of ionic conductivity with $1 / T$ for selected electrolyte compositions of $\mathrm{p}(\mathrm{TMC})_{n} \mathrm{LiPF}_{6}$. 


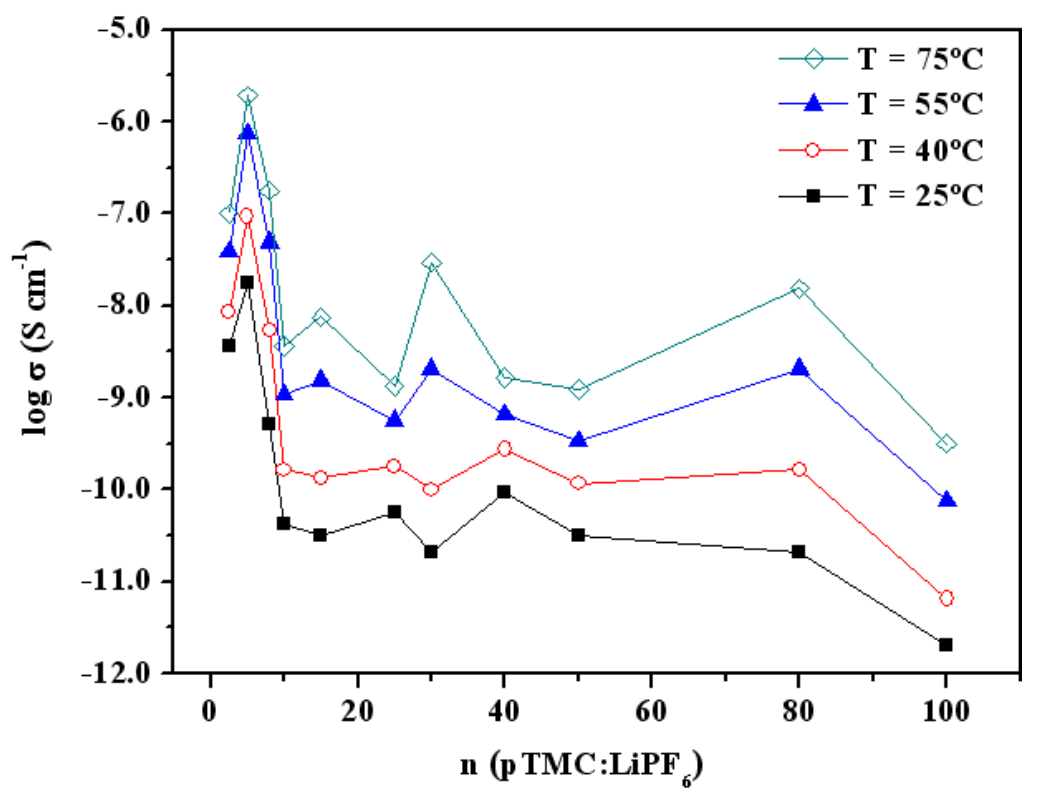

Figure 5. Composition dependence of the ionic conductivity of the $\mathrm{p}(\mathrm{TMC})_{n} \mathrm{LiPF}_{6}$ electrolytes. 


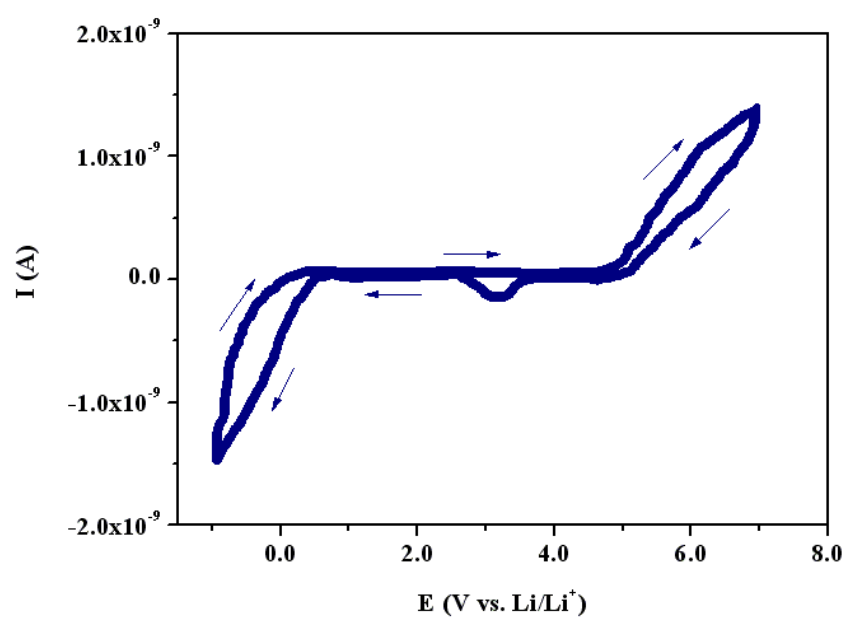

Figure 6. Voltammogram of $\mathrm{p}(\mathrm{TMC})_{30} \mathrm{LiPF}_{6}$ electrolyte at a $25 \mu \mathrm{m}$ diameter gold microelectrode versus $\mathrm{Li} / \mathrm{Li}^{+}$. Initial sweep direction is anodic and sweep rate is $100 \mathrm{mVs}^{-1}$. 
